\title{
Yoğun Bakım Hemşirelerinin Ahlaki Duyarlılığı ile Etik Karar Verebilme Düzeyi Arasındaki İlişkinin Belirlenmesi
}

\author{
Birgül CERITT*, Esra ÖZTÜRK**
}

$\ddot{O} \mathbf{z}$

Giriş: Yoğun bakımda yatan hastaların genellikle hayati riskinin olması, yakın izlem gerektirmesi ve özel bakım gereksinimlerinin olması, bu birimde görev yapan hemşirelerin etik sorunlarla karşılaşma sıklığını artırabilmektedir. Dolayısıyla yoğun bakım hemşirelerinin karşı karşıya kaldığı etik sorunları tanıması ve etik karar verebilme becerisine sahip olması, bakımın etik standartlara uygun şekilde verilebilmesi açısından önemlidir. Amaç: Bu çalışmanın amacı, yoğun bakım hemşirelerinin ahlaki duyarlılığı ile etik karar verebilme düzeyi arasındaki ilişkinin belirlenmesidir. Yöntem: Bu çalışmada ilişkisel tarama modeli kullanılmıştır. Veriler 103 yoğun bakım hemşiresinden elde edilmiştir. Verilerinin toplanmasında Tanımlayıcı Bilgi Formu, Ahlaki Duyarlılık Anketi ve Hemşirelik Etik İkilem Testi kullanılmıștır. Araştırma verilerinin değerlendirilmesinde tanımlayıcı istatistikler ve Pearson korelasyon analizi kullanılmıştır. Bulgular: Yoğun bakım hemşirelerinin ahlaki duyarlılık puan ortalaması $77.33 \pm 17.053$ belirlenmiştir. Hemşirelerin en az çatışma (12.15 \pm 4.486$)$, en fazla ise oryantasyon $(9.05 \pm 3.856)$ alt boyutunda etik duyarlılık gösterdikleri saptanmıştır. Hemşirelerin ilkesel düşünme puan ortalaması $46.79 \pm$ 6.293 ve pratik düşünme puan ortalaması $19.01 \pm 3.994$ olarak hesaplanmıştır. Ahlaki duyarlılık alt boyutlarından sadece bütüncül yaklaşım $(\mathrm{r}=.24 ; \mathrm{p}=.013)$ ve toplam ahlaki duyarlılık $(\mathrm{r}=.20 ; \mathrm{p}=.040)$ ile yoğun bakım hemşirelerinin ilkesel düşünme düzeyi arasında pozitif yönlü, anlamlı ve çok zayıf ilişki belirlenmiştir. Ahlaki duyarlılık ile hemşirelerin pratik düşünme düzeyi arasında anlamlı bir ilişki tespit edilmemiştir. Sonuç: Araştırma sonucunda, yoğun bakım hemşirelerinin ahlaki duyarlılık düzeyinin yüksek olduğu, etik karar verirken etik ilkeleri ve çevresel faktörleri ortalamanın üzerinde dikkate aldıkları görülmektedir. Yoğun bakım hemşirelerinin ahlaki duyarlılı̆̆ının artması etik karar verebilme düzeylerine olumlu şekilde yansıyabilir.

Anahtar Kelimeler: Ahlaki Duyarlılık, Etik Karar Verebilme, Yoğun Bakım, Hemşire.

\section{Abstract}

Determination of the Relationship Between Intensive Care Nurses' Moral Sensitivity and Ethical Decision Making Level Background: The fact that hospitalized patients in intensive care units are generally at risk of life, require close monitoring and have special care needs may increase the happening of ethical problems encountered by nurses working in this unit. Therefore, it is important for intensive care nurses to recognize these ethical problems they face and have the ability to make ethical decisions, in order to provide care in accordance with ethical standards. Objective: The aim of this study is to determine the relationship between intensive care nurses' moral sensitivity and their levels of ethical decision-making. Method: Relational screening model was used in this study. The data were obtained from 103 intensive care nurses. Descriptive Information Form, Moral Sensitivity Questionnaire and Nursing Dilemma Test were used to collect data. Descriptive statistics and Pearson correlation analysis were used to evaluate the research data. Results: The average moral sensitivity score of intensive care nurses was $77.33 \pm 17.053$. It was found that nurses showed ethical sensitivity at least in the sub-dimension of conflict $(12.15 \pm 4.486)$ and at most in the sub-dimension of orientation $(9.05 \pm 3.856)$. The nursing principled thinking mean score of nurses was $46.79 \pm 6.293$, while the practical consideration mean score was $19.01 \pm 3.994$. Among the moral sensitivity sub-dimensions, only holistic approach $(\mathrm{r}=.24 ; \mathrm{p}=.013)$ and total moral sensitivity $(\mathrm{r}=.20 ; \mathrm{p}=.040)$ were found to have a positive, significant and very weak relationship with nursing principal thinking levels of the intensive care nurses. No significant relationship has been found between moral sensitivity and practical consideration levels of nurses. Conclusion: As a result of the study, it is seen that intensive care nurses have a high level of moral sensitivity, and they consider ethical principles and environmental factors above the average while making ethical decisions. Increased moral sensitivity of intensive care nurses may positively be reflected on their level of ethical decision-making. Keywords: Moral Sensitivity, Ethical Decision Making, Intensive Care, Nurse.

Geliş tarihi: 03.07.2020 Kabul tarihi: 04.02.2021

$\mathrm{Y}$ oğun bakım üniteleri, kritik hastaları desteklemeyi ve tedavi etmeyi amaçlayan, ileri teknolojik cihazlar ile donatılmış, 24 saat boyunca hastaların hayati belirtilerinin takip edildiği ve multidisipliner bir anlayışla hizmet sunmayı amaçlayan birimler olarak tanımlanmaktadır (2). Bu birimlerde çalışan hemşireler, yoğun bakım eğitimi almış donanımlı sağlık profesyonelleri olarak multidisipliner ekibin içerisinde önemli bir yere sahiptirler. Yoğun bakım hemşirelerinin, hastanın durumunda ortaya çıkan değişiklikleri ilk saptayan ve acil durumlarda ekip içinde hızlı karar alması gereken meslek üyesi olarak karmaşık ve beklenmedik bir anda ortaya çıkan sorunlarla daha sık karşılaştığı belirtilmektedir (3). Özellikle de yoğun bakımda tedavi edilmekte olan kritik hastaların bakımı sırasında etik sorunlar sık yaşanmaktadır (4). Bu birimlere kabul edilen hastaların durumunun genellikle hayati risk içermesi, yakın izlem gerektirmesi, özel bakım ve tedavi gereksinimlerinin olması $(5,6)$ yoğun bakım hemşirelerine etik açıdan sorumluluklar yüklemektedir. Bilinçsiz, konfüzyonda, mekanik ventilatöre bağlı ya da fiziksel tespit uygulanan yoğun bakım hastaları sağlık personeline bağımlı ve bakıma muhtaç; dolayısıyla savunmasız ve kolay örselenebilir konumdadır. Bu özellik, bakım verilenin korunmasını, bakım verenin ise ahlaki sorumluluğunun farkında ve duyarlı olmasını gerektirir (7). Bu bağlamda yoğun bakımlarda görev yapan hemşirelerin, sağlık bakım hizmeti sunarken karşı karşıya kaldığı etik sorunları tanıması, soruna ilişkin uygun çözümler üretebilmesi ve etik karar verebilme becerisine sahip olması gerekmektedir.

* Doç. Dr., Bolu Abant İzzet Baysal Üniversitesi Sağlık Bilimleri Fakültesi, Hemşirelik Bölümü, Hemşirelik Esaslar1 AD, Bolu. E-mail: birgulcerit@yahoo.com.tr, Telefon: +90 37425410 00, ORCID ID: 0000-0003-0007-4205 **Uzm.Hem., Bolu İzzet Baysal Devlet Hastanesi, Bolu. Telefon: +90 37427045 75, E-mail: ar_se_4515@hotmail.com, ORCID ID: 0000-0001-8350-3348 
Sağlık bakım hizmeti verilirken ortaya çıkan etik sorunları ayırt edebilmek, diğer bir deyişle etik duyarlılığa sahip olmak etik karar verebilme sürecinde önemlidir. Berggren ve ark.(8) etik karar vermeyi; birbiriyle çatışan seçeneklerin olduğu bir durumda, sistematik düşünme biçimiyle ahlaki açıdan en doğru eyleme karar verilmesini içeren mantıksal bir süreç olarak tanımlamaktadır. Hemşirelik mesleği açısından etik karar verme, hemşirenin etik sorun içeren herhangi bir durum karşısında bilişsel yetilerini kullanarak bir yargıda bulunması ve bu yargının gerektirdiği eylemin uygulamaya yansıtılmasını ifade eder (9). Etik karar verebilme, sağlık alanında ortaya çıkan etik sorunların farkında olunması ve etik sorunlara yönelik profesyonel bir yaklaşım sergilenebilmesi bakımından önemlidir (1). Yoğun bakım hemşirelerinin giderek artan etik sorunlarla yüz yüze kalması onların akıl yürütme, muhakeme yapabilme ve hasta birey adına alınan karar / eylemlerin doğru ya da yanlış olduğuna ilişkin ahlaki bir yargıda bulunmasını, yani etik karar vermesini gerektirmektedir (1). Hemşirelerin yoğun bakımda karar vermek durumunda kaldığ 1 ve ahlaki sıkıntı yaşadığı en önemli durumlar arasında iletişim, tedaviyi sonlandırma ve terminal sedasyon yer almakatdır. Bu durumlara ilişkin karar veririken zorlandıkları ve hastaya yarar sağladığına inanmadıkları uygulamalarda daha fazla tükenmişlik yaşadıkları bilinmektedir $(10,11)$. Yoğun bakım birimlerinde hemşireler hasta merkezli bakım vermekte, hastayı yakından izlemekte ve iletişimde bulunmaktadır. Bakımın fiziksel ve psikolojik açıdan yakın ilişsiyi gerektirdiği dikkate alındığında, hemşirelerin hastalarının en güçsüz ve mahrem yönlerini görebildiği; onların acılarına, yalnızlık, umutsuzluk vb. duygularına tanık olabildiği ifade edilebilir (7). Bu durum hemşirenin kimi zaman hastalar ile ilgili vicdani yükü olan güç kararlar almasına, kimi zaman da uygun olmayan seçenekler arasında karar verememesine ve ikilemde kalmasına neden olabilmektedir (7).

Sonuç olarak yoğun bakımlarda etik sorunların yaygın şekilde yaşandığı ve konunun her geçen gün öneminin arttığı bilinmektedir. Yoğun bakım hemşirelerinin sorunları önceden fark edebilecek düzeyde bilgi ve etik duyarlılığa sahip olması beklenmektedir (12). Hemşirelerin etik duyarlılıklarının ve etik karar verebilme becerilerinin gelişmiş olması, onların hasta bakımına ilişkin uygun kararlar alabilmeleri ve hasta bakımında profesyonel davranış sergileyebilmeleri bakımından önemlidir. Ancak yoğun bakım hemşireleri ile yapılan çalışmaların çoğu hemşirelerin etik duyarlılığının orta düzeyde olduğunu $(2,3,13,14)$, etik karar verirken sistematik bir etik karar verme modeli kullanmadıkları (15), ahlaki sıkıntı yaşadıkları (16) ve orta düzeyde etik karar verebilme becerisine sahip olduklarını (17) göstermektedir. Konunun önemi ve literatürde yoğun bakım hemşirelerinin ahlaki duyarlılığı ile etik karar verebilme düzeyi arasındaki ilişkiyi ortaya koyan çalışmaya rastlanmamış olmasından yola çıkarak bu çalışma planlanmıştır. Elde edilecek sonuçların konuya ilişkin farkındalık oluşturacağı, gelecekte yapılması planlanan çalışmalar için yol gösterici olacağı, literatüre ve yoğun bakım hastalarına etik davranışlarla örtüşen profesyonel yaklaşımın sergilenebilmesinde yoğun bakım hemşirelerine ve kurum yöneticilerine katkı sağlayacağı düşünülmektedir.

Amaç

$\mathrm{Bu}$ araştırmanın amacı yoğun bakım hemşirelerinin ahlaki duyarlılığı ile etik karar verebilme düzeyi arasındaki ilişkinin belirlenmesidir.

Araştırma Soruları

- Yoğun Bakım Hemşirelerinin ahlaki duyarlılık düzeyi nedir?

- Yoğun Bakım Hemşirelerinin etik karar verebilme düzeyi nedir?

- Yoğun Bakım Hemşirelerinin ahlaki duyarlılığı ile etik karar verebilme düzeyi arasında ilişki var mıdır?

\section{Yöntem}

\section{Araştırmanın Tipi}

Bu çalışma, ilişkisel tarama modeli kullanılarak tanımlayıcı tipte yapılmıştır.

Araştırmanın Yapıldı̆̆ Yer

Araştırma Karadeniz Bölgesi'nde yer alan bir il merkezinde bulunan dört hastanede gerçekleştirilmiştir.

Araştırmanın Evren ve Örneklemi

Araştırmanın evrenini bir il merkezinde yer alan ve yoğun bakım ünitesi bulunan hastanelerde görev yapan 141 hemşire oluşturmuştur. Çalışmada evrene ulaşabilme olanağ 1 bulunduğundan örneklem seçimine gidilmemiş ve çalışma evren üzerinden gerçekleştirilmiştir. Buna göre araştırma çalışmaya katılmaya gönüllü olan ve veri toplam formlarının tam olarak geri döndüğü 103 yoğun bakım hemşiresi ile tamamlanmıştır (Cevaplanma oranı, \%73.05).

\section{Verilerin Toplanmast}

Araştırma verileri araştırmacılar tarafından oluşturulan ve hemşirelerin tanımlayıcı özelliklerine ilişkin bilgilerin elde edilmesine yönelik yedi sorudan oluşan Tanımlayıcı Bilgi Formu, Ahlaki Duyarlılık Anketi (ADA) ve Hemşirelik Etik İkilem Testi (HEIT) ile 1-30 Mayıs 2015 tarihleri arasında toplanmıştır. Veri toplama formları yoğun bakım hemşirelerine dağıtılmış ve doldurduktan sonra araştırmacılar tarafından teslim alınmıştır.

\section{Veri Toplama Araçlart}

Tanımlayıcı Bilgi Formu: Araştırmaya katılan hemşirelerin yaş, cinsiyet, eğitim düzeyi, medeni durumu, hemşire olarak çalışma süresi, yoğun bakımda çalışma süresi ve etik konusunda eğitim alma durumuna yönelik soruların yer aldığ formdur. Ahlaki Duyarlılık Anketi (ADA): Orijinal adı "Moral Sensitivity Questionnaire (MSQ)" olan ve Türkçe'ye Ahlaki Duyarlılık Anketi (ADA) olarak çevrilen anket, 1994 yılında Lutzen tarafından geliştirilmiştir. Tosun (2018) tarafından Türkçe'ye uyarlama çalışması yapılmıştır (18). Ahlaki Duyarlılık Anketi hekim ve hemşirelerde ahlaki duyarlılığı test etmek amacıyla kullanılmaktadır. Otuz ifadeden oluşan yedili likert tipte olan anketteki ifadeler, 1 puan = Tamamen katılıyorum, 7 puan $=$ Hiç katılmıyorum arasında değerlendirilmektedir. Bir puan tamamen katılma yönünde yüksek duyarlılığı, 7 puan hiç katılmıyorum yönünde düşük duyarlılığı ifade etmektedir. ADA'dan alınabilecek toplam puan 30-210 arasında değişmektedir. Puanın yüksek 
Araştırma

olması etik açıdan düşük duyarlılığı, puanın düşük olması ise etik açıdan yüksek duyarlılığı göstermektedir. Anket otonomi (7 madde), yarar sağlama (4 madde), bütüncül yaklaşım (5 madde), çatışma (3 madde), uygulama (4 madde) ve oryantasyon (4 madde) olmak üzere altı alt boyut ve 30 maddeden oluşmaktadır. Altboyutlarda yer almayan 3., 23., 26. maddeler Lutzen'in yaptığı faktör analizi sonucunda herhangi bir alt boyutun kapsamında yer almamıştır. Tosun (2018)'un çalışmasında ölçeğin Cronbach alfa değeri .84 olarak belirlenmiştir (18). Bu çalışmada ölçeğin Cronbach alfası .79 bulunmuştur.

Hemşirelik Etik İkilem Testi (HEIT): Orijinal adı "Nursing Dilemma Test” olan ve Türkçe'ye Hemşirelik Etik İkilem Testi olarak çevrilen test, 1981 yılında Crisham tarafindan geliştirilmiştir. Cerit (2010) tarafından Türkçe'ye uyarlama çalışması yapılmıştır (9). Bu test senaryolaştırılmış altı etik ikilem içermektedir. Her bir ikilem üç bölümden oluşmaktadır. Bu çalışmada, etik karar verebilmeye ilişkin İlkesel Düşünme (ID) ve Pratik düşünme (PD) puanlarının hesaplandığı testin ikinci bölümü değerlendirmede kullanılmıştır.

Testin ikinci bölümünde hemşirelerin etik ikilem içeren senaryoyu düşünerek buna yönelik yaklaşımında göz önünde bulundurabileceği altı maddelik ifade yer almaktadır. Hemşirelerden bu ifadeler arasında en önemli olanını seçmesi ve kendisine göre önem sırası doğrultusunda numaralandırması beklenmiştir. Testin bu bölümüne verilen yanıtlar doğrultusunda hemşirelerin ID ve PD düzeylerinin belirlenmesi amaçlanmıştır. İlkesel Düşünme, hemşirelikte etik karar verirken etik ilkeleri göz önüne almaya verilen önemi göstermektedir. Pratik düşünme ise, hemşirelerin etik sorunlara ilişkin karar vermesinde hasta sayısı, kullanılabilir kaynakların sayısı, kurumsal politikalar, hemşireler tarafından yönetimin verdiği desteğin algılanma ölçüsü ve hekim kontrolü gibi çevresel faktörlere verdiği önemi ölçmektedir. Hemşirelerin bu belirtilen altı ifadeyi önem sırasına göre numaralandırarak verdikleri yanıtlardan ID ve PD düzeyi puanı hesaplanmaktadır. Her bir ikilemden elde edilen ID ve PD puanlarının ayrı ayrı toplanmasıyla toplam ID ve PD puanları belirlenir. Testte ulaşılabilecek ID puanı 18-66, PD puanı ise 6-36'dır (9).

\section{Araştırmanın Dĕğişkenleri}

Araştırmanın bağımsız değişkeni ahlaki duyarlılık düzeyi, bağımlı değişkeni ise etik karar vermedir.

\section{Verilerin Dĕgerlendirilmesi}

Verilerin analizi SPSS 17.0 paket programı kullanılarak yapılmıştır. Tanımlayıcı özelliklere ilişkin verilerin değerlendirilmesinde frekans ve yüzde hesapları, hemşirelerin ahlaki duyarlılığı ve etik karar verebilme düzeyini belirlemek için de ortalama ve standart sapma değerlerinden yararlanılmıştır. Bu çalışmada kullanılacak istatistiklerin belirlenebilmesi için verilerin normal dağılım gösterip göstermediği Kolmogorov-Smirnov testi ile tespit edilmiştir. Kolmogorov-Smirnov testi sonuçları her iki ölçek toplam puanları için verilerin normal dağılım gösterdiğini ortaya çıkarmıştır $($ ADA için K-S = .79; $\mathrm{p}=$ .550 ; HEIT İD için K-S = 1.02; $\mathrm{p}=.247$; HEIT PD için $\mathrm{K}-\mathrm{S}=.96 ; \mathrm{p}=.312$ ). Bu sonuca dayalı olarak yoğun bakım hemşirelerinin ahlaki duyarlılı̆̆ı ile etik karar verebilme düzeyi arasındaki ilişkinin değerlendirilmesinde Pearson korelasyon analizi kullanılmıştır. Literatürde korelasyon katsayısının gücü ile ilgili tanımlamalar, .00-.25 çok zayıf, .26-.49 zayıf, .50-.69 orta, .70-.89 kuvvetli, .90-1.00 arasında olması durumunda ise çok kuvvetli olarak belirtilmiştir (19). Araştırmada değişkenler arasındaki ilişki bu tanıma dayalı olarak yorumlanmıştır. Çalışmanın post-hoc güç analizi PASS 11 programı kullanılarak yapılmıştır. \% 0 korelasyona dayalı olarak 103 kişide yapılan post-hoc analize göre ahlaki duyarlılık (ADA) ve etik karar verme (ID) arasında \% 68'lik güç düzeyi yakalanmıştır.

\section{Araştırmanın Etik Yönü}

Araştırmanın yürütülebilmesi için etik kurul izni (31.03.2015 tarihli ve 2015/42 sayılı), araştırmanın uygulanacağı kurumlardan uygulama izni ve çalışmada kullanılan ölçeklerin yazarlarından e-posta yolu ile kullanım izni alınmıştır. Çalışmaya gönüllü olarak katılan hemşirelere araştırma ve veri toplama araçları hakkında uygulama öncesi bilgilendirme yapılmış ve hemşirelerin sözel onamları alınmıştır.

\section{Bulgular}

Tablo 1 incelendiğinde; hemşirelerin \%86.4 $(\mathrm{n}=89)$ 'ünün kadın, yaş ortalamalarının $28.14 \pm 6.43$ y1l $(\min =18$, max = 42), \%40.8 ( $\mathrm{n}=42)^{\prime}$ inin Sağlık Meslek Lisesi mezunu ve \%50.5 (n= 52)'inin bekar olduğu belirlenmiştir. Hemşirelerin \%43.7 $(\mathrm{n}=$ 45)'sinin 1-5 yıldır hemşire olarak çalıştı̆̆ $1, \% 48.5(\mathrm{n}=50)$ 'inin $1-5$ yıldır yoğun bakımda görev yaptığ1 ve \%73.8 (n = 76)'inin de etik konusunda eğitim almadığ1, geriye kalan \%26.2 (n=27) kişinin ise hizmet içi eğitim ve hemşirelik eğitimleri sırasında dersleri içinde bir konu olarak aldığı belirlenmiştir (Tablo 1). 
Araştırma

Tablo 1. Hemşirelerin Tanımlayıcı Özelliklerinin Dă̆ılımı

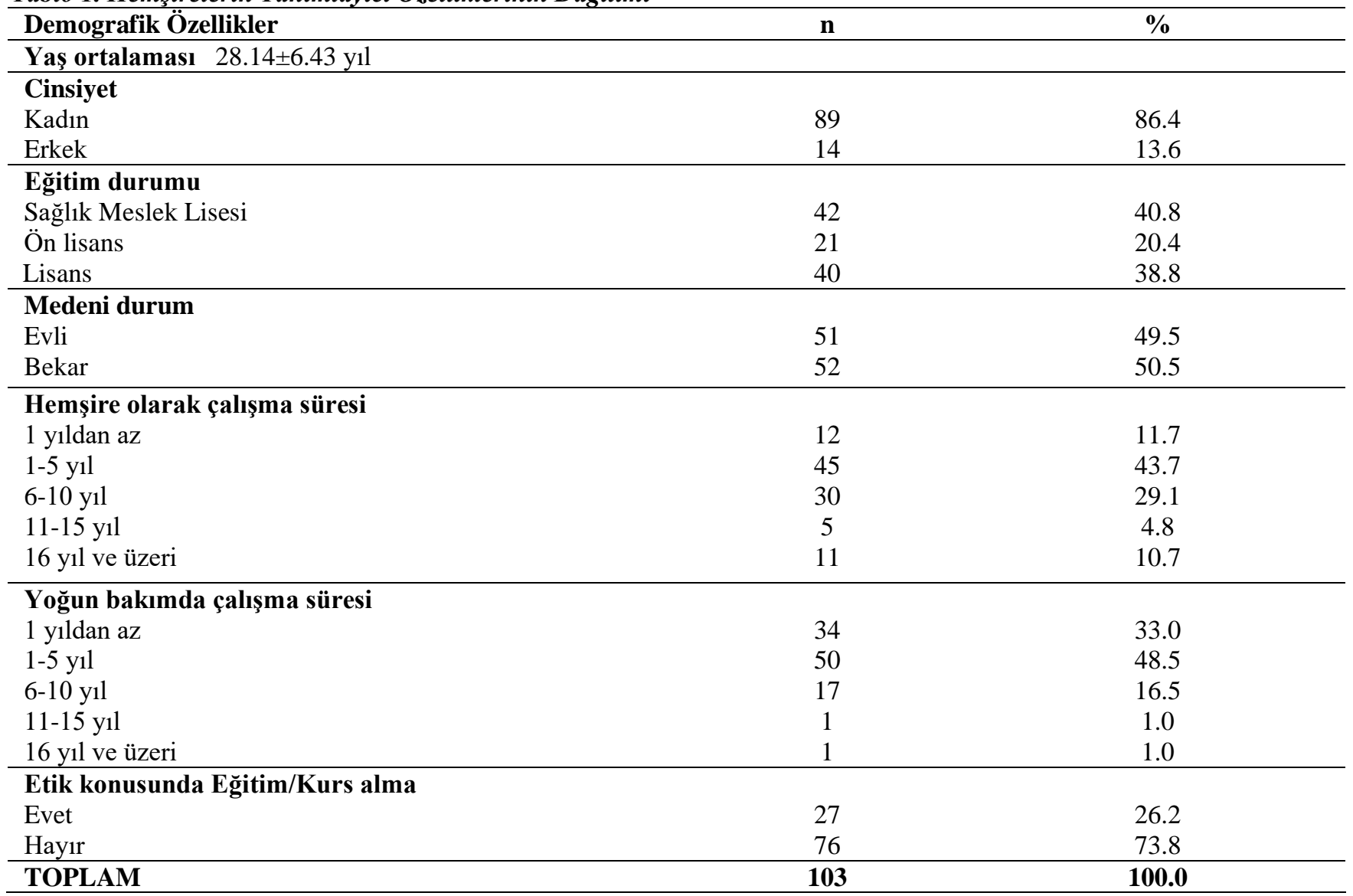

Tablo 2'ye göre, yoğun bakım hemşirelerinin en az çatışma (12.15 \pm 4.486$)$, en fazla ise oryantasyon $(9.05 \pm 3.856)$ alt boyutunda etik duyarlılık gösterdikleri görülmektedir. Hemşirelerin ahlaki duyarlılık düzeyi yüksek belirlenmiştir $(77.33 \pm$ 17.053) (Tablo 2).

Tablo 2. Hemşirelerin ADA ve Alt Boyutlarına İlişkin Puan Ortalaması

\begin{tabular}{lccccc}
\hline ADA Alt Boyutları & Madde Sayısı & Min & Max & Ort. \pm SS & Ölçek Puanı \\
\hline Otonomi & 7 & 7 & 36 & $18.33 \pm 5.800$ & $7-49$ \\
Yarar Sağlama & 4 & 4 & 28 & $12.21 \pm 4.134$ & $4-28$ \\
Bütüncül Yaklaşım & 5 & 5 & 26 & $12.75 \pm 4.519$ & $5-35$ \\
Çatışma & 3 & 3 & 21 & $12.15 \pm 4.486$ & $3-21$ \\
Uygulama & 4 & 4 & 24 & $12.35 \pm 4.084$ & $4-28$ \\
Oryantasyon & 4 & 4 & 20 & $9.05 \pm 3.856$ & $4-28$ \\
Toplam * ADA & $\mathbf{3 0}$ & $\mathbf{3 3}$ & $\mathbf{1 4 5}$ & $\mathbf{7 7 . 3 3} \pm \mathbf{1 7 . 0 5 3}$ & $\mathbf{3 0 - 2 1 0}$ \\
\hline
\end{tabular}

*ADA: Ahlaki Duyarlılık Anketi

Tablo 3'te hemşirelerin İD (46.79 \pm 6.293) ve PD (19.01 \pm 3.994) puan ortalamasının ortalamanın üzerinde olduğu saptanmıştır (Tablo 3).

Tablo 3. Hemşirelerin Hemşirelik Etik İkilem Testi’nden Aldığ İlkesel Düşünme ve Pratik Düşünme Puan Ortalaması

\begin{tabular}{lcccc}
\hline${ }^{*}$ HEIT Puanları & Min. & Max. & Ort. \pm SS & Ölçek Puanı \\
\hline İlkesel Düşünme & 30 & 62 & $46.79 \pm 6.293$ & $18-66$ \\
Pratik Düşünme & 10 & 30 & $19.01 \pm 3.994$ & $6-36$ \\
\hline
\end{tabular}

${ }^{*}$ HEİT: Hemşirelik Etik İkilem Testi

Yoğun bakım hemşirelerinin ahlaki duyarlılığı ile etik karar verebilme düzeyi arasındaki ilişkiyi gösteren korelasyon analizi sonuçları Tablo 4'de yer almaktadır. Buna göre ahlaki duyarlılık alt boyutlarından sadece bütüncül yaklaşım $(\mathrm{r}=.24 ; \mathrm{p}=.013)$ ve toplam ADA ( $\mathrm{r}=.20 ; \mathrm{p}=.040)$ ile hemşirelerin ID düzeyi arasında pozitif yönlü, anlamlı ve çok zayıf ilişki belirlenmiştir. Otonomi, yarar sağlama, çatışma, uygulama ve oryantasyon alt boyutları ile ID arasında anlamlı bir ilişki saptanmamıştır. Ahlaki duyarlılık ile yoğun bakım hemşirelerinin PD düzeyi arasında anlamlı bir ilişkiye rastlanmamıştır (Tablo 4). 
Araştırma

\begin{tabular}{lcc} 
Tablo 4. Hemşirelerin Ahlaki Duyarlılı̆̆ı ile Etik Karar Verebilme Düzeyi Arasındaki Korelasyon Analizi Sonuçları \\
\hline ADA ve Alt Boyutları & Ilkesel Düşünme & Pratik Düşünme \\
\hline Otonomi & .124 & .060 \\
Yarar Sağlama & .077 & -.115 \\
Bütüncül Yaklaşım & $.244^{*}$ & -.059 \\
Çatışma & .023 & -.060 \\
Uygulama & .183 & .015 \\
Oryantasyon & .122 & .043 \\
Toplam ${ }^{* *}$ ADA & $.203^{*}$ & -.026 \\
\hline
\end{tabular}

"p<.05, ${ }^{* *}$ ADA: Ahlaki Duyarlılık Anketi

\section{Tartışma}

Araştırmada yoğun bakım hemşirelerinde ahlaki duyarlılığın yüksek olduğu saptanmıştır. Konuya ilişkin yapılmış çalışmalar incelendiğinde, bazı çalışmalarda yoğun bakım hemşirelerinin ahlaki duyarlılığı bu çalışmadakinden daha düşükken $(2,3,13,14,20)$ bazı çalışmalarda ise daha yüksek belirlenmiştir (21,22). Araştırma sonuçları arasında bu farklılığın, araştırmaların farklı kurumlarda çalışan hemşirelerle yapılmış olmasından, kurumsal etik iklim algısının farklılık gösterebilmesinden ve hemşirelerin etik sorun içeren durumlarla karşılaşma olasılıklarından kaynaklanabileceğini düşündürmüştür. Ahlaki duyarlılık hemşirenin etik sorunu fark edebilmesi, soruna ilişkin çözümler üretebilmesi ve çatışmayı önleyebilmesi açısından gereklidir (23,24). Yoğun bakım hemşirelerinin ahlaki duyarlılığı, mesleki profesyonelliği yansıtmanın yanı sıra hastalara verilecek bakımının niteliğini doğrudan etkileyecek bir unsurdur (3). Bu bağlamda çalışmada hemşirelerin ahlaki duyarlılıklarının yüksek olması, hemşirelerin bakım hizmeti sunarken karşılaşacakları etik sorunları ayırt edebileceklerini ve sorunun çözümüne ilişkin uygun yaklaşım sergileyebileceklerini gösterebilir.

Araştırmada yoğun bakım hemşirelerinin etik karar verirken, etik ilkeleri gözönünde bulundurmaya verdikleri önem ortalamanın üzerinde belirlenmiştir. Bu sonuca göre, hemşirelerin karşılaşmış olduğu etik sorunlar karşısında, istendik düzeyde olmasa da etik ilkeleri dikkate alarak düşündüğü söylenebilir. Literatürde farklı birimlerde çalışan hemşirelerle yapılmış çalışma sonuçları karşılaştırıldığında birbirinden farklı sonuçlar elde edildiği görülmektedir. Bazı çalışmalarda bu çalışmadakine yakın sonuçlar elde edilmişken $(1,17,25-30)$ bazı çalışmalarda hemşirelerin İD düzeyi bu çalışmadaki yoğun bakım hemşirelerinin İD düzeyinden daha yüksek (9,31-34), bazı araştırmalarda ise daha düşük belirlenmiştir (35-37). Araştırma sonuçlarının farklılık göstermesinde, katılımcıların farklı ülkelerde, kurumlarda ve birimlerde görev yapması, karar vermeye yol gösteren rehberlerin kullanımı, eğitim ve otonomi düzeyinin etkili olabileceği düşünülmektedir. İlkesel düşünme, etik karar gerektiren durumlarda sorunun çözümüne ilişkin izlenecek yola veya eyleme karar verme aşamasında kritiktir. Eyleme karar verirken ahlaki bir tutum sergileyebilmek açısından etik ilkeler yol göstericidir (9). Ancak konuya ilişkin literatür incelendiğinde yoğun bakım hemşirelerinin etik sorunu çözmeye çalışırken yardıma gereksinimleri olduğu, etik sorunun nasıl çözüldüğü konusunda bilgi sahibi olmadıkları (22), etik sorunlar karşısında eyleme karar verme ve uygulama konusunda zorlandıkları (21) veya soruna ilişkin çözüm üretemedikleri görülmektedir (3,22). Oysaki yoğun bakım hemşireleri, hastanın durumunda ortaya çıkan değişiklikleri ilk saptayan ve acil durumlarda ekip içinde hızlı karar alması gereken sağlık profesyoneli olarak, karmaşık ve beklenmedik bir anda ortaya çıkan sorunlarla daha sık karşılaşmakta ve hızlı karar vermek zorunda kalabilmektedir $(38,39)$. Bu durumda yaşanan etik sorunları çözümleyebilmek ve uygun karar verebilmek için etik ilkelerin rehberliği önemlidir. Bu çalışmada yoğun bakım hemşirelerinin etik karar verme durumunda kaldığında etik ilkeleri göz önünde bulundurmaya özen gösterdiği ancak ilkesel düşünme düzeyinin istendik seviyede olmadığı söylenebilir.

Araştırmada yoğun bakım hemşirelerinin etik sorunlara ilişkin karar verirken, çevresel faktörleri ortalamanın üzerinde önemsedikleri belirlenmiştir. Literatürde farklı birimlerde çalışan hemşirelerle yapılan araştırma sonuçları incelendiğinde, çoğu çalışmada bu çalışmadakine benzer sonuçlar elde edilmişken $(1,9,17,25,27,29,33)$ bazı çalışmaların ise farklılık gösterdiği $(26,32,34,35)$ tespit edilmiştir. Araştırma sonuçlarının tutarsızlık göstermesinde, çalışmaların farklı ülkelerde gerçekleştirilmiş olması, katılımcıların farklı birimlerde çalışması, ekip işbirliği ve görev tanımlarına ilişkin algı, yönetici desteği, kurumsal prosedür ve politikaların yansımalarının olabileceği söylenebilir. Etik karar verme sürecinde çevresel faktörlerin önemli etkisi olabilmektedir. Hemşireler karşılaşmış oldukları etik sorunlara ilişkin karar verirken, durumsal baskıları göz önünde bulundurmakta ve bu baskılar nedeniyle de kararlarını değiştirebilmektedirler. Örneğin, etik sorunun çözümünde kendi adalet kavramlarıyla çelişen hastane politikaları, hekime itaat, zaman kısıtlılı̆̆ı, kaynakların kontrolü ve mesleki yetki ve sorumluluklara ilişkin belirsizlikler gibi birçok çevresel faktörü göz önünde bulundurmak, hemşirelerin karar verme sürecini etkileyebilmektedir $(1,33)$. Dolayısıyla hemşireler değerlerini, yaşam deneyimlerini, bilişsel becerilerini, ahlaki duyarlılığını ve muhakeme yeteneğini etik karar verme ve bu karara uygun eylemde bulunma sürecine yansıtırken pek çok çevresel faktörün etkisinde kalmaktadır (9,40). Çalışmanın sonucuna dayalı olarak yoğun bakım hemşirelerinin etik karar verirken çevresel faktörlerin etkisinde kaldığ 1 , karar vermede güçlük ve belirsizlik yaşadığı ifade edilebilir.

Araştırmada ahlaki duyarlılık alt boyutlarından sadece bütüncül yaklaşım ve toplam ADA ile hemşirelerin İD düzeyi arasında pozitif, anlamlı ve çok zayıf bir ilişki olduğu belirlenmiştir. Etik karar verebilme becerisini kullanmada ahlaki duyarlılık önemli bir etkiye sahiptir (41). Ahlaki duyarlılık hastanın gereksinimini saptamak için bakım verenin farkındalığını, sözel ve sözel olmayan belirtileri ve davranışları anlama becerisini gerektirir (42). Bu bağlamda, yoğun bakım hemşirelerinin daha savunmasız, pek çok açıdan hemşireye bağımlı, otonomi kaybı olan, genellikle hayati risk taşıyan ve iletişim kurmakta güçlük yaşayan hastalara bakım verdiği ve bakımla ilgili ahlaki sorumlulukları dikkate alındığında bu beceriye sahip olmanın önemi artmaktadır. Dolayısıyla yoğun bakım hemşirelerinin hastaların bakım ihtiyacına duyarlı bir biçimde yanıt 
Araştırma

verebilmesinde ahlaki duyarlılığa sahip olması ön koşul ve bütüncül bakımın önemli bir bileşeni olarak görülmektedir (43). Hemşirenin bütüncül yaklaşım çerçevesinde hem hastaya zarar vermeyecek hem de hastanın bütünlüğunnü koruyabilecek uygulamalarda bulunması önemlidir. Bu süreçte yoğun bakım hemşiresinin çalışma ortamında deneyimlediği etik sorunları tanıyabilmesi, bu sorunların çözümüne ilişkin karar verme sürecinde profesyonel tutum ve davranış sergilemesi, etik ilkelerin önem ve önceliğini göz önünde bulundurması nitelikli ve ahlaki standartalar uygun bir bakım sunabilmesi açısından gereklidir. Buna göre araştırmada yoğun bakım hemşirelerinin ahlaki duyarlılığı ile ilkesel düşünme düzeyi arasında pozitif ilişki olduğunun ortaya çıkması, hemşirelerin etik bilince sahip, ahlaki sorumluluklarının farkında, duyarlı ve nitelikli bir hasta bakımını gerçekleştirmek için çaba göstereceklerini düşündürebilir.

\section{Kisıtlılıklar}

$\mathrm{Bu}$ çalışmanın sonuçları, araştırmaya katılan yoğun bakım hemşireleri ve onların bu çalışmada kullanılan ölçeklere verdiği yanıtlarla sınırlıdır. Ayrıca araştırmanın orta büyüklükte bir ilde yürütülmesi, yoğun bakım hemşire sayısının sınırlı olması ve buna bağlı olarak post-hoc güç değeri de dikkate alındığında ileri çalışmalar daha büyük örneklem grubu ile yapılabilir.

\section{Sonuçların Uygulamada Kullanımı}

Araştırma sonucunda yoğun bakım hemşirelerinin en az çatışma, en fazla ise oryantasyon alt boyutunda etik duyarlılık gösterdikleri ve ahlaki duyarlılık düzeylerinin yüksek olduğu belirlenmiştir. Yoğun bakım hemşirelerinin etik karar verirken etik ilkeleri ve çevresel faktörleri ortalamanın üzerinde dikkate aldıkları belirlenmiştir. Ahlaki duyarlılık alt boyutlarından sadece bütüncül yaklaşım ve toplam ADA ile hemşirelerin ID düzeyi arasında pozitif yönlü, anlamlı ve çok zayıf bir ilişki olduğu belirlenmiştir. Ahlaki duyarlılık ile yoğun bakım hemşirelerinin PD düzeyi arasında ise anlamlı bir ilişki tespit edilmemiştir. Bu doğrultuda etik duyarlılık ve etik karar verebilme becerisini kazandırmaya dönük, mezuniyet öncesi etik dersinin hemşirelik müfredatında zorunlu ders olarak okutulması, mezuniyet sonrası teorik ve uygulamanın bir arada olduğu hizmet içi eğitim programlarının yapılması, karar vermeyi etkileyen çevresel faktörlerin belirlenmesi ve azaltılmasına dönük kurumsal düzenlemelerin yapılması ve mesleki otonominin desteklenmesi önerilebilir.

Araştırmadan elde edilen sonuçların; yoğun bakım hemşirelerinin etik karar verirken yaşadıkları içsel çatışmayı azaltmaya ve etik karar verebilme becerisini geliştirmeye dönük eğitim programlarının düzenlenmesine, kararlarını etkileyen çevresel faktörlerin sınırlandırılmasına yönelik kurumsal politikalar ve etik iklimin geliştirilmesine, yoğun bakım hemşirelerinin ahlaki duyarlılığı ile etik karar verebilme düzeyi arasındaki ilişkiyi ortaya koyan ileri çalışmaların yapılmasına rehberlik edebileceği düşünülmektedir.

\section{Bilgilendirme}

Bu çalışmada yazarların katkı beyanı: Fikir B.C; tasarım B.C., E.Ö.; verilerin toplanması ve analizi B.C., E.Ö.; literatür tarama ve makale yazımı B.C., E.Ö.; eleştirel değerlendirme B.C. tarafından yapılmıştır. Çalışma araştırma ve yayın etiğine uygun yürütülmüştür. Araştırma için 31.03.2015 tarih ve 2015/42 sayı numarası ile etik kurul izni alınmıştır. Bütün yazarlar bu makalenin son halini onaylamaktadır. Bu çalışmada çıkar çatışması bulunmamaktadır. Bu çalışmada finansal destek alınmamıştır. Araştırmanın bütçesi araştırmacılar tarafından karşılanmıştır. Araştırmaya katılım gösteren yoğun bakım hemşirelerine teşekkür ederiz.

\section{Kaynaklar}

1. Cerit B, Dinç L. Ethical decision-making and professional behaviour among nurses: a correlational study. Nurs Ethics [online]. 2013;20(2):200-212. URL: https://journals.sagepub.com/doi/10.1177/0969733012455562. 01.08.2019

2. Araç B, Doğan R, Sarıtaş S. Determining the moral sensitivity of intensive care nurses. Int J Med Invest [online]. 2018;7(1):88-97. URL: http://intjmi.com/article-1-306-en.pdf. 01.08.2019

3. Başak T, Uzun Ş, Arslan F. Yoğun bakım hemşirelerinin etik duyarlılıklarının incelenmesi. Gülhane Tıp Dergisi [online]. 2010;52(1):76-81. URL: http://cms.galenos.com.tr/Uploads/Article 33397/GMJ-52-76-En.pdf. 01.08.2019

4. Yüzkat N, Çeğin MB, Soyoral L, Göktaş U, Özkan B. Terminal dönemdeki bir hastada karşılaşılan etik belirsizlik sekizinci kateter. Journal of Clinical and Experimental Investigations [online]. 2015;6(2):196-198. URL: https://pdfs.semanticscholar.org/eba7/be9b8114f8654b6c0dbef701ad5fbc113e4b.pdf. 03.08.2019

5. Öztürk H. Yoğun bakım hemşirelik hizmetlerinde etik. Türkiye Klinikleri J Med Ethics [online]. 2010;18(3):183-191. URL: https://www.turkiyeklinikleri.com/article/tr-yogun-bakim-hemsirelik-hizmetlerinde-etik-58915.html. 03.08.2019

6. Nyholm L, Koskinen C. Understanding and safeguarding patient dignity in intensive care. Nurs Ethics [online]. 2017;24(4):408-418. URL: https://journals.sagepub.com/doi/full/10.1177/0969733015605669. 03.08.2019

7. Dinç L. Bakım kavramı ve ahlaki boyutu. Hacettepe Üniversitesi Sağlık Bilimleri Fakültesi Hemşirelik Dergisi 2010;17(2):74-82.

8. Berggren I, Bégat I, Severinsson E. Australian clinical nurse supervisors' ethical decision-making style. Nurs Health Sci [online]. 2002;4(1-2):15-23. URL: https://onlinelibrary.wiley.com/doi/full/10.1046/j.1442-2018.2002.00096.x. 01.09.2019

9. Cerit B. Hemşirelik Etik İkilem Testi'nin geçerlik-güvenirlik çalışması ve hemşirelerin etik karar verebilme düzeyi. Hacettepe Üniversitesi Sağlık Bilimleri Fakültesi Hemşirelik Dergisi 2010;17(2):47-67.

10. Teixeira C, Ribeiro O, Fonseca AM, Carvalho AS. Ethical decision-making in intensive care units: a burnout risk factor? Results from a multicentre study conducted with physicians and nurses. J Med Ethics 2013;40(2):97-103. 
Araştırma

11. Meltzer LS, Huckabay LM. Critical care nurses' perceptions of futile care and its effect on burnout. Am J Crit Care [online]. 2004;13(3):202-8. URL: https://aacnjournals.org/ajcconline/article-abstract/13/3/202/283/Critical-Care-NursesPerceptions-of-Futile-Care?redirectedFrom=fulltext. 25.11.2020

12. Kırşan M, Yıldırım G, Ceylan B, Korhan EA, Uyar M. Yoğun bakım ünitelerinde etik sorunlar: Sistematik derleme. Türkiye Klinikleri Journal Medical of Ethics [online]. 2018; 26(2):57-65.URL: https://www.turkiyeklinikleri.com/article/en-yogun-bakim-unitelerinde-etik-sorunlar-sistematik-derleme-81807.html. $\underline{03.08 .2019}$

13. Dikmen Y. Yoğun bakım hemşirelerinde etik duyarlılığın incelenmesi. Cumhuriyet Nurs J 2013;2(1):1-7.

14. Başar Z, Çilingir D. Evaluating ethical sensitivity in surgical intensive care nurses. Nurs Ethics [online]. 2019;26(7-8): 2384-2397. URL: https://journals.sagepub.com/doi/pdf/10.1177/0969733018792739. 04.12.2020

15. Çobanoğlu N, Algıer L. A qualitative analysis of ethical problems experienced by physicians and nurses in Intensive Care Units in Turkey. Nurs Ethics [online]. 2004;11(5):444-458. URL: https://doi.org/10.1191/0969733004ne723oa. 03.12.2020

16. Viney C. A phenomenological study of ethical decision-making experiences among senior intensive care nurses and doctors concerning withdrawal of treatment. Nurs Crit Care. 1996;1(4):182-187

17. Rızalar S, Baltacı N, Yıldızeli Topçu S, Sanioğlu Gökçe A. Ameliyathane ve yoğun bakım hemşirelerinde etik karar verme düzeyi. Arch Health Sci Res. 2020;7(2):129-3620.

18. Tosun H. Ahlaki Duyarlılık Anketi Türkçe geçerlilik ve güvenirlik uyarlaması. J Contemp Med [online]. 2018;8(4):316321. URL: https://dergipark.org.tr/tr/download/article-file/626492. 03.09.2019

19. Ural A, Kılıç İ. Bilimsel Araştırma Süreci ve SPSS ile Veri Analizi (4. bs.). Ankara: Detay Yayıncılık; 2013.

20. Alan H, Tiryaki Şen H, Şıpkın S. Yoğun bakım ve ameliyathane hemşirelerinin etik ikilemlere karşı duyarlılıkları: üniversite hastanesi örneği. Cumhuriyet Hemşirelik Dergisi 2017;6(1):26-33

21. Izadi A, Imani H, Khademi Z, FariAsadi NF, Hajizadeh N, Naghizadeh F. Moral sensitivity of critical care nurses in clinical decision making and its correlation with their caring behavior in teaching hospitals of Bandar Abbas in 2012. Iranian J Med Ethics Hist Med [online]. 2013;6(2):43-56. URL: http://ijme.tums.ac.ir/article-1-5014-en.html. 11.08.2019

22. Karademir N, Ergün Y. JCU akreditasyon belgesine sahip özel hastanelerde çalışan yoğun bakım hemşirelerinin etik duyarlılı̆̆ ve etik ikilemleri. 2. Uluslararası 8. Ulusal Yoğun Bakım Hemşireliği Kongresi; 10-13 Ekim 2018; Marmaris.

23. Kim YS, Kang SW, Ahn JA. Moral sensitivity relating to the application of the code of ethics. Nurs Ethics [online]. 2012;20(4):470-478. URL: https://doi.org/10.1177/0969733012455563. 05.08.2019

24. Lovett BJ, Jordan AH. Levels of moralization: a new conception of moral sensitivity. J Moral Educ. 2010;39(2):175-189.

25. Baysal E, Sarı D, Erdem H. Ethical decision-making levels of oncology nurses. Nurs Ethics [online]. 2019;26(7-8):22042212. URL: https://doi.org/10.1177/0969733018803662. 01.09.2019

26. Amiri R, Gaeeni M, Ahmari H, Momenyan S. The Relationship between moral reasoning and the caring behavior of nurses in emergency departments of Qom, $2015 . \quad$ IJEC. 2017;1(3):1-10 URL: http://ijec.ir/article-1-58-en.html. 04.09.2019

27. Sabancıoğulları S, Uslu Kol E, Arslantaş AT, Toğantemur F, Ülker F. Hemşirelerin etik karar verme düzeyi ile profesyonel benlik kavramları arasındaki ilişkinin incelenmesi. DEUHFED [online]. 2018;11(2):105-112. URL: https://dergipark.org.tr/tr/download/article-file/752803.01.08.2019

28. Zirak M, Moghadasian S, Abdollahzadeh F, Rahmani A. Level of ethical development in nurses working in trainingtreatment hospitals affiliated to Tabriz University of Medical Sciences, Tabriz, Iran. Qom Univ. Med. Sci. J. [online]. 2012;6(3):32-39.

URL:https://applications.emro.who.int/imemrf/Qom_Univ_Med_Sci_J/Qom_Univ_Med_Sci_J_2012_6_3_32_39.pdf?_g $\mathrm{a}=2.227449758 .2058487303 .1600030306-2136936147.1600030306 .11 .09 .2020$.

29. Fazljoo E, Borhani F, Abbaszadeh A, Dadgari A. Assessment of moral reasoning ability of the nurses in dealing with moral dilemmas. J Med Ethics [online]. 2016;10(36):47-54. URL: https://www.researchgate.net/publication/311625484_Assessment_of_moral_Reasoning_Ability_of_the_Nurses_in_deali ng with moral dilemmas. 11.09.2020

30. Safavi F, Ebrahimi H, Eshtanab H, Khodadadi E, Fooladi M. Relationship between demographic characteristics and ethical reasoning of nurses working in medical wards. J Clin Diagnostic Res [0nline]. 2018;12(8):LC01-LC04. URL: https://doi.org/10.7860/JCDR/2018/32521.11883. 04.09.2019

31. Rizalar S, Baltaci N. Ethical decision-making levels of nurses and it's affecting factors. Int J Caring Sci [online]. 2020;13(1):42-52. URL: http://www.internationaljournalofcaringsciences.org/docs/6_rizarlar_original_13_1.pdf. 11.09.2020

32. Yurttaş A, Kara Kaşıkçı M, Ağaçdiken S, Kavuran E, Şirin M. Hemşirelerin ve hemşirelik öğrencilerinin etik karar verme düzeylerinin karşılaştırılması. Türkiye Klinikleri J Med Ethics [online]. 2014; 22(1):1-8. URL: https://www.turkiyeklinikleri.com/article/en-hemsirelerin-ve-hemsirelik-ogrencilerinin-etik-karar-verme-duzeylerininkarsilastirilmasi-68396.html. 01.08.2019

33. Crisham P. Measuring moral judgement in nursing dilemmas. Nurs Res 1981;30(2):104-110.

34. Arsang-Jang S, Khoramirad A, Pourmarzi D, Raisi M. Relationship between spiritual intelligence and ethical decision making in Iranian Nurses. J Humanist Psychol [online]. 2020; 60(3):330-341. URL: https://journals.sagepub.com/doi/10.1177/0022167817704319.11.09.2020

35. Demirsoy N, Türe Yılmaz A, Şaylıgil Ö. Hemşirelerin etik ikilemlere yaklaşımları: bir kamu hastanesi örneği. JHS 2018;15(3):1568-1583. URL: https://j-humansciences.com/ojs/index.php/IJHS/article/view/5354/2598. 05.09.2019 
Araştırma

36. Koohi A, Khaghanizade M, Ebadi A. The relationship between ethical reasoning and demographic characteristics of nurses. IJME [online]. 2016;9(1):26-36. URL: http://ijme.tums.ac.ir/article-1-5659-en.html. 11.09.2020

37. Badri Gargari R, Mahmoodi F, Soltani N, Laripour R. Investigating and comparison the ethical reasoning level of nursing students Aja university of medical sciences with nurses working in one of their affiliated hospitals. Military Caring Sciences [online]. 2020;7(1):46-52. URL: http://mcs.ajaums.ac.ir/article-1-323-en.pdf. 11.09.2020

38. İbrahimoğlu Ö. Son dönem yoğun bakım hastalarının bakımında etik sorunlar ve etik yaklaşım. Sağlık Akademisyenleri Dergisi [online]. 2017;4(3):216-220. URL: https://dergipark.org.tr/tr/download/article-file/751805. 07.09.2019

39. Hakverdioğlu Yönt G, Akın Korhan E, Dizer B, Koyuncu R. Hemşirelerin yoğun bakım ünitelerinde yaşadıkları etik sorunların belirlenmesi. Türkiye Klinikleri J Med Ethics [online]. 2013;21(2):7478.URL:https://www.turkiyeklinikleri.com/article/en-hemsirelerin-yogun-bakim-unitelerinde-yasadiklari-etik-sorunlarinbelirlenmesi-65327.html. 04.08.2019

40. Fry ST, Johnstone MJ. Ethics in nursing practice: a guide to ethical decision making. 3th Edition. USA: Blackwell Science Ltd; 2008.

41. Cerit B, Özveren H. Effect of hospital ethical climate on the nurses' moral sensitivity. European Res J. 2019;5(2):282290.

42. Schluter J, Winch S, Holzhauser K, Henderson A. Nurses' moral sensitivity and hospital ethical climate: A literature review. Nurs Ethics [online]. 2008;15(3):304-321. URL: https://doi.org/10.1177/0969733007088357. 11.08.2019

43. Gastmans C. A fundamental ethical approach to nursing: some proposals for ethics education. Nurs Ethics [online]. 2002;9(5):494-507. URL: https://doi.org/10.1191/0969733002ne539oa. 04.09.2019 